\title{
Natural factor impact on atmospheric electric field variations in Kamchatka
}

\author{
Pavel Firstov ${ }^{1,2,}$, Nina Cherneva ${ }^{1}$, and Rinat Akbashev ${ }^{2}$ \\ ${ }^{1}$ Institute of Cosmophysical Research and Radio Wave Propagation FEB RAS \\ ${ }^{2}$ Kamchatka Branch of Geophysical Service RAS
}

\begin{abstract}
The paper briefly describes a site network which registers atmospheric electric field strength (AEF $\left.\mathrm{V}^{\prime}\right)$. The scheme of natural processes affecting the formation of the local atmospheric electric field is considered. AEF $V^{\prime}$ disturbances on ground flux meters are described. They were recorded when two eruptive clouds from Shiveluch volcano eruption were passing by. Key words: atmospheric electric field, potential gradient, electrostatic flux meter, volcanic clouds
\end{abstract}

\section{Introduction}

Electric field of the near ground atmospheric layer is an important object for the investigation in the context of development of numerical characteristics of the process referring to the Global Electric Circuit (GEC) and in the development of the approaches to determine and to describe the nature and mechanisms of electric effects at the crustatmosphere boundary. The principles of GEC formation are described in detail in many papers from which a review [1] deserves special attention. This paper shows the latest results which give better understanding of the physical processes occurring in the GEC.

Of special interest is the investigation of Atmospheric Electric Field (AEF) variations in the conditions of ever-present disturbances not only of global but regional and local scales as well. It is accepted that the height of the «equalizer level», that is an isopotential surface along which the potential equalizes for quite a short time, is $\sim 60 \mathrm{~km}$. Consequently, variations in AEF $V^{\prime}$ potential gradient on the surface caused by potential distribution inhomogenuities on the «equalizer level» should also have a size close to the regional scale. Smaller AEF $V^{\prime}$ scales falling outside the regional limits refer to local scales.

In spite of many investigations of AEF behavior, the nature and the mechanisms of local electric fields require a detailed study in each concrete area that is due to the complexity of the problem and the multifactorial local processes forming the AEF. In Kamchatka peninsular, investigation of AEF is of special interest because of the specific natural conditions of this region at the background of industrially clean atmosphere of Kamchatka.

Intensity of geodynamic processes in Kuril-Kamchatka subduction zone (earthquakes and volcano eruptions), fast changeability of meteorological values caused by high cyclonic activity in the north-western part of the Pacific ocean determine the diversity of local processes affecting the AEF. Thus, the complex of meteorological, geophysical and space

${ }^{*}$ Corresponding author: firstov@emsd.ru 
factors, simultaneously acting and significantly changing in time, complicate the AEF behavior in Kamchatka.

\section{Instrumentation and observation method}

Investigation of atmospheric electric field in Kamchatka has been carried out from the beginning of 90-ies of the latest century when an electrostatic flux meter «Pole-2» with analogue registration [2] was installed at «Paratunka» (PRT) observatory of IKIR FEB RAS (Fig. 2a) to measure AEF $V^{\prime}$. Then, a system for AEF $V^{\prime}$ data storage and processing in the digital form was developed [3,4]. Moreover, a lightning direction finder is in operation at «Paratunka» observatory [5]. It is included into to the global WWLLN network and the data from it allow us to determine the source coordinates of volcanic lightning discharges accompanying explosive eruptions in Kamchatka [6]. The information on the planet lightning activity including that on lightning discharges from a definite threshold accompanying eruptions is available on the site of WWLLN network http://webflash.ess.washington.edu/.
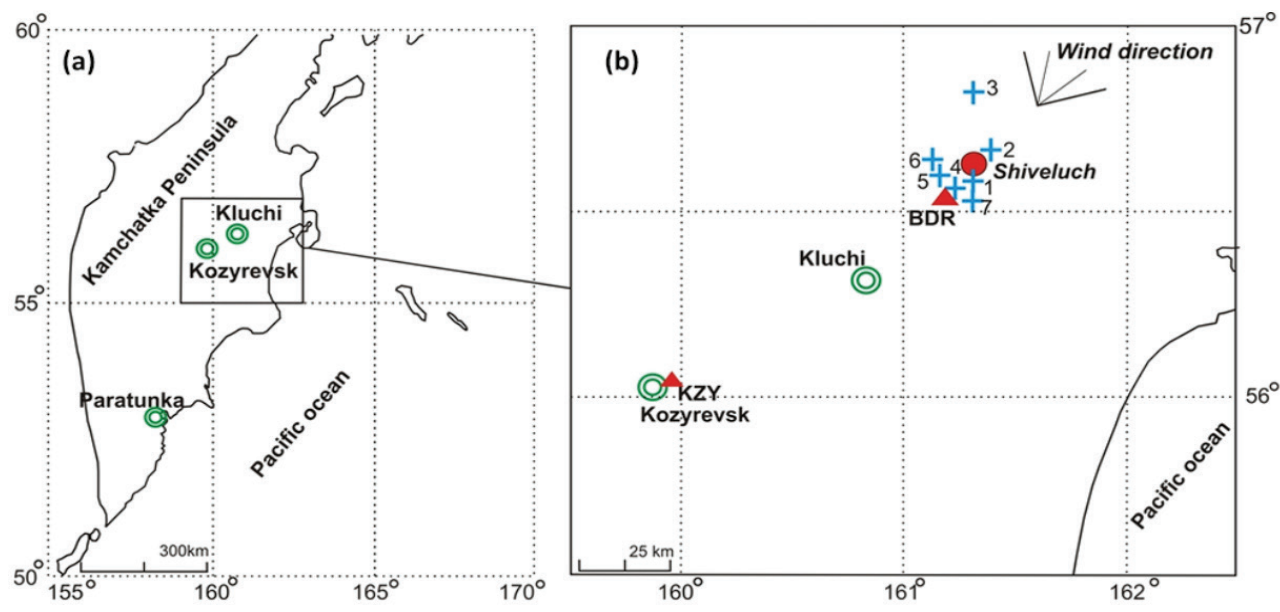

Fig. 1. Scheme of arrangement of AEF strength registration sites on Kamchatka peninsula (a), arrangement of observation sites in the region of the Northern Group of volcanoes and location of discharges from volcanic lightning during Shiveluch volcano eruption on November 16, 2014 (b).

AEF $V^{\prime}$ registration in the central part of Kamchatka peninsula is of special interest as long as it is possible to compare the behaviors of AEF $V^{\prime}$ unitary and annual variations of the continental and coastal regions of Kamchatka. The Northern Group of volcanoes is also located here including four active volcanoes of Kamchatka (Kluchevskoy, Bezymyanny, Ploskiy Tolbachik, Shiveluch volcanoes) (Fib. 1b). Frequent explosive eruptions of these volcanoes increase the possibility of registration of AEF $V^{\prime}$ under volcanic plumes. Thus, an electrostatic flux meter EF-4 was installed at «Kozyrevsk» (KZY) site of Kamchatka Branch of Geophysical Service RAS (KB GS RAS) in 2013 (Fig. 2b). It is described in the paper [7]. Moreover, a meteorological station Vasiala wxt520 is in operation at KZY which allows us to measure weather parameters that is of great importance for AEF $\mathrm{V}^{\prime}$ data interpretation. Some time later, EF-4 was installed at Kluchi (KLY) seismic site. 

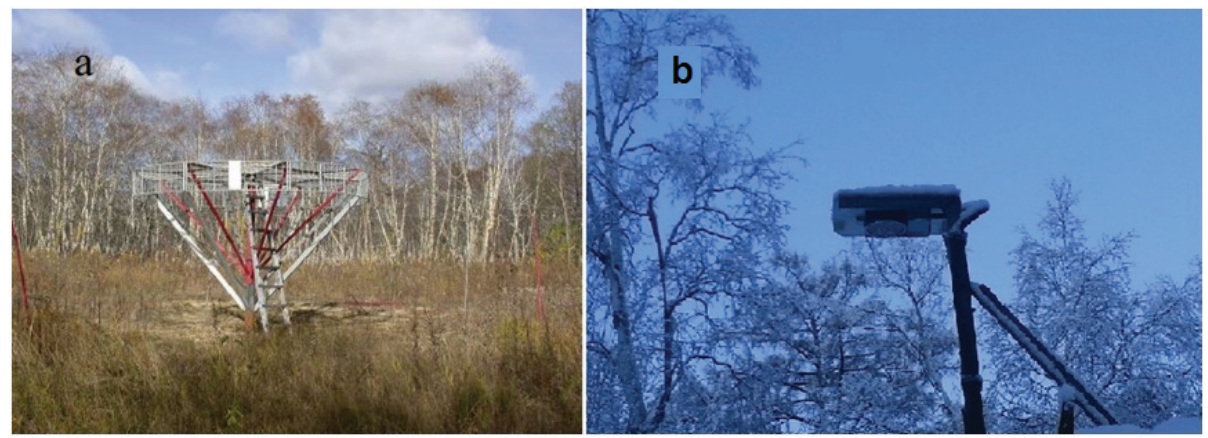

Fig. 2. General view of the equipotential surface on which «Pole-2» flux meter is mounted at PRT observatory (a), flux meter EF-4 installed in KZY with obturator downwards (b).

Monitoring of the volcanic activity of the Northern Group is carried out by Kamchatka Branch of the Federal Research Center «Geophysical Service of RAS» (KB FRC GS RAS) based on the investigation of some volcano seismicity. Radiotelemetric seismic station (RTSS) network is in operation in the region of the Northern Group of volcanoes. The closest to the volcano «Baydarnaya» (BDR) and «Semkorok» RTSS are located 10 and 15 $\mathrm{km}$ from the volcano crater (Fib. 2b) and register the time of an explosion beginning with the accuracy up to a second.

Meteorological parameters (air pressure, temperature and humidity) are observed at «Petropavlovsk» and «Kluchi» meteorological observatories of Kamchatka Division on Hydrometeorology and Environment Monitoring located in Petropavlovsk-Kamchatksiy and Kluchi. Height balloon atmospheric sounding is also carried out twice a day and the obtained data are published on the site http://www.esrl.noaa.gov/raobs/intl/intl2000.wmo.

\section{Main natural factors affecting local electric field}

Based on the analysis of long-term observations of AEF $V^{\prime}$ variations applying meteorological data, that of cosmic radiation intensity, geomagnetic field variations, radon exhalations and VLF electromagnetic radiation, the papers [8, 9] suggest a phenomenological model of natural and near space process impact on AEF state (Fig. 3).

One of the local scales is the height of radon mixing layer upper boundary which varies from hundreds of meters in winter on a windless night to 6-8 kilometers on a hot and windy summer day. We should also take into account that radon penetration into the atmosphere may be blocked by soil upper layer freezing and snow cover [10]. Some universal scale for this area can, evidently, be determined by geological-tectonic structure of the region. Conductivity of the near ground layer is primary determined by light ion concentration which depends not only on the ionization by radon but by many factors which form local AEFs sometimes masking the unitary variations determined by GEC.

The most significant factors affecting the local AEF are the following $[8,9]$ :

- radon outflow into the atmosphere,

- cosmic ray flux variations,

- light and heavy ion balance change at the times of dawn and dusk,

- ionopheric electric current potential effect of AEF potential. 


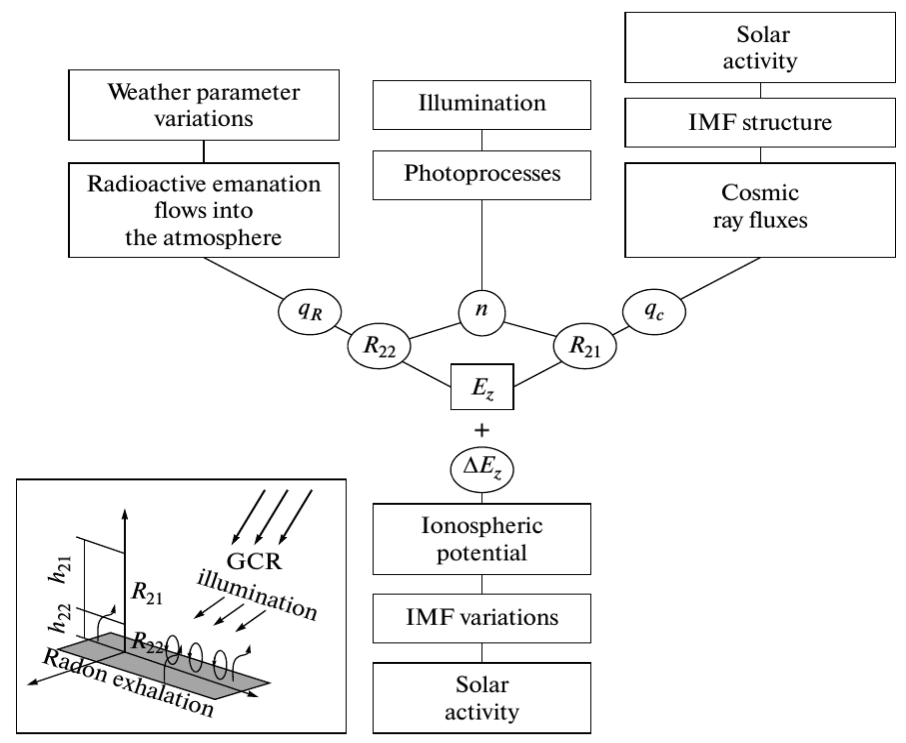

Fig. 3. Scheme of the processes of atmospheric electric field formation in the presence of factors affecting its value in the near ground layer. $\mathrm{H}_{21}$ and $\mathrm{H}_{22}$ ionization regions in the atmosphere by cosmic ray and radon exhalation with resistance $\mathrm{R}_{22}$ and $\mathrm{R}_{21}$ in these regions.

AEF strength is non-uniformly distributed along the height. For the total difference of the earth-ionosphere potential of about $300 \mathrm{kV}, \sim 270 \mathrm{kV}$ fall in the «lower» 20-kilometer layer and $30 \mathrm{kV}$ fall within the rest $80 \mathrm{~km}$. That means that the resistance of the «lower» layer significantly determines the current in the whole earth-ionosphere column.

We denote the resistance of the column upper part, depending only on external factors, by $R_{1}$, and the resistance of the column lower part by $R_{2}=R_{21}+R_{22}$, where: $R_{21}$ is the resistance of $h_{21}$ layer that value is determined by cosmic rays; $\mathrm{R}_{22}$ is the resistance of the variable thickness layer $h_{22}$ in which cosmic ray ionization is enlarged by radon ionization (Fig. 3). The thickness of $h_{22}$ depends on the air turbulent mixing and potential drop in «radon» layer can be written as $\mathrm{U}_{22}=\mathrm{U} \cdot \mathrm{R}_{22} /\left(\mathrm{R}_{1}+\mathrm{R}_{21}+\mathrm{R}_{22}\right)$.

The main factor determining the local AEF is the atmospheric near ground layer resistance which primary depends on the ionizing effect of cosmic rays and radon. Moreover, the diurnal variations of radon outflow from the soil are determined by atmospheric pressure variations and the seasonal ones depend on the soil upper layer permeability determined by soil temperature.

Meteorological factors play a key role in the formation of AEF annual variation. Higher values of field intensity in winter are associated with the fact that radon outflow in winter months drops due to the soil freezing and thick snow cover in Kamchatka [10]. This process may also be affected by significant decrease of sunlight (Paratunka $53^{\circ} \mathrm{N}$ ) that causes the increase of heavy ion quantity due to photoattachment. Heavy ions have low mobility and the atmospheric near ground layer conductivity decreases in winter time that cause AEF $E_{Z}$ increase.

Air conductivity is determined by light ion concentration, charge and mobility. "Average» light ion mobility in the air at the sea level equals $\mu=1.5 \mathrm{sm}^{2} /(\mathrm{V} \cdot \mathrm{s})$. Heavy ions, dust particles and molecular clusters with attached molecular ions and electrons, have low mobility and do not almost participate in electric current rise. Thus, at dawn, $E_{Z}$ slowly grows to $10 \%$ within three hours due to the increased turbulence [9]. 


\section{Electrization of eruptive clouds forming during Shiveluch volcano eruptions}

Natural factors, unique for the Russian Federation, which form electric structures of the local scale in Kamchatka peninsula, are explosive eruptions of volcanoes. Eruptive clouds forming during this process are electric structures which are somewhat close to meteorological clouds. Sheveluch volcano has actively erupted within the latest five years. It is the most northern one among the active volcanoes of Kamchatka $\left(56^{\circ} 47^{\prime} \mathrm{N}, 157^{\circ} 56^{\prime} \mathrm{E}\right)$ with extrusive dome of $2500 \mathrm{~m}$ above the sea level (Fig. 1b). Within the latest decade, its eruptions, determined by slow magma squeezing out and extrusive dome formation, are periodically accompanied by strong ash explosions. At that, in the cases of wind southern and south-western directions, eruptive cloud trajectories pass the sites KZY and KZV.

It is generally know that volcanic clouds (plumes) bear an electric charge which is recorded by ground-based devices located near the cloud propagation traces. Eruptive cloud electrization takes place by two reasons, by magma breakage (damage) and gravitative differentiation of ash particles in eruptive column and plume $[11,12]$. In this case, bipolar charges are formed and volcanic lightning of different intensity occur.

An explosive eruption with eruptive cloud height of $13000 \mathrm{~m}$ above the sea level occurred on Sheveluch volcano on November 16, 2014 at 10:17. At KZY (Kozyrevsk site) located $110 \mathrm{~km}$ to the south-west, a positive anomaly with the duration of 1.5 hour was registered 2 after the event on a AEF $V^{\prime}$ record (Fig. 4a). Positive disturbance coincided in time with eruptive plume passage at the distance of $25 \mathrm{~km}$ from KZY at the heights of 8 and $12 \mathrm{~km}$, that was fixed by the data obtained on the basis of wind stratification of the atmosphere and satellite images [6].

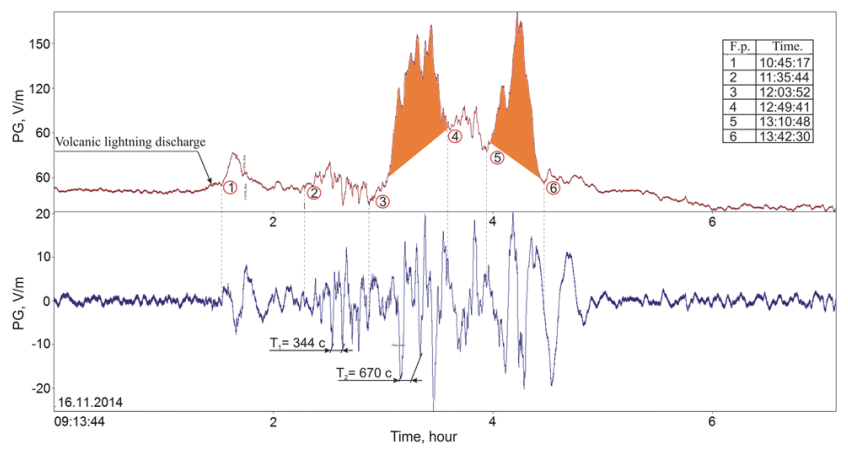

Fig. 4. A fragment of AFE strength record at KZY site with characteristic reference points (a); AEF V' curve after high frequency filtering with frp $=0.0008333 \mathrm{~Hz}(20 \mathrm{~min})(\mathrm{b})$. Numbers in circles indicate the reference points in the signal record from a passing eruptive cloud.

Fair weather conditions (FWC) were observed before and after the eruption. The AEF $\mathrm{V}^{\prime}$ background value was $\sim 50 \mathrm{~V} / \mathrm{m}$ (Fig. 4a). Seven discharges were registered after the eruption within $20 \mathrm{~min}$. Discharge locations are shown in Fig. 4a. The first weak variations of AEF $V^{\prime}$ were observed from 10:45 and almost in two hours after the eruption, clear beginnings of two anomalies are distinguished (at 12:04 and at 13:10) with the total duration of 1.5 hour (Fig. 4a) when AEF V' value reached its maximum value of $170 \mathrm{~B} / \mathrm{m}$. FWC give the ground to consider the AEF $V^{\prime}$ variations as a consequence of a passing eruptive plume. 
We can note that «higher-frequency» oscillations with the amplitude of $\sim 10 \mathrm{~V} / \mathrm{m}$ are observed before the clearly defined AEF $\mathrm{V}^{\prime}$ anomalies within 78 minutes. The anomalies are also complicated by «higher-frequency» oscillations. The signal with the duration of more than tree hours, in which five segments could be defined, was filtered by a highfrequency filter with fгр $=0.0008333 \mathrm{~Hz}(20 \mathrm{~min})$. The segments distinguished by kinematic and dynamic parameters are well defined on the filtered signal (Fig. 4b).

The beginning of the signal almost coincides with the time of the latest discharge from the volcanic lightning which occurred at the distance of $90 \mathrm{~km}$ from KZY (Fig. 1b). Oscillations with 12-15-minute periods are registered in AEF $V^{\prime}$ «high-frequency» range variations both on the first and the last segments. For the second and third segments, oscillations with shorter periods of 5-6 minutes are characteristic. Evidently, charged particles interact in the result of convective and turbulent processes in an eruptive cloud and regions with different $\mathrm{AEF} \mathrm{V}^{\prime}$ value are formed.

As it was shown in the paper [13], volcanic clouds have a tripole structure. The upper part of a cloud compound of vapor and aerosols has a positive charge. The middle part, represented by fine ash, has a negative charge. And the lower part, enriched in large-sized ash in the result of gravitation, also has a positive charge. At significant distances from the volcano, when eruptive clouds are mainly composed of aerosol and ash of micrometric dimensions, they have a positive charge that is observed in our case.

A great success for the observers of eruptive cloud charge evolution was the Siveluch volcano eruption on June 14, 2017 when a lucky combination of wind direction and FWC was observed that allowed us to record AEF V' variations during an eruptive cloud passage over KLY and KZV sites.

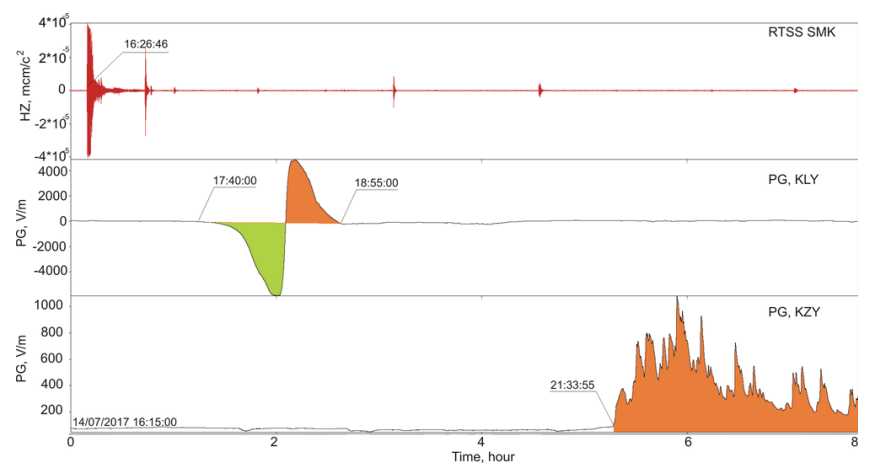

Fig. 5. Record fragment of ground displacement rate at RTSS SMK (a) and AEF strength at KLY and KZY (b, c) during the passage of the eruptive cloud from Shiveluch volcano eruption on June 14, 2017.

In contrast to the previous eruption, much greater quantity of ash was thrown into the atmosphere during this eruption that is indicated by AEF $V^{\prime}$ large values both at KLY and KZY. The significant amount of ash precipitated at KLY at the distance of $45 \mathrm{~km}$ from the volcano ( $\sim 300 \mathrm{~g} / \mathrm{m} 2$ according to N.A. Zharinov's oral report) agrees with the large scale of bipolar signal amplitude of $6<V^{\prime}<5 \mathrm{kV} / \mathrm{m}$ (Fig. 5b). Based on the signal form, we can assume that the eruptive cloud discharge is a horizontal dipole the axis of which is oriented along the propagation line [14]. The time of signal arrival, whereas its duration is an hour and fifteen minutes at KLY site, agrees with the wind stratification of the atmosphere obtained during atmosphere height sounding at Kluchi.

The one-polar signal from the eruptive cloud plume at KZY lasted for more than three hours with $V_{M A X}^{\prime}=900 \mathrm{~V} / \mathrm{m}$ (Fig. 5c). 


\section{Conclusions}

Natural factors, unique for the Russian Federation, which form electric structures of the local scale in Kamchatka peninsula, are explosive eruptions of volcanoes. Eruptive clouds forming during this process are electric structures which are somewhat close to meteorological clouds. Sheveluch volcano has actively erupted within the latest five years. It is the most northern one among the active volcanoes of Kamchatka $\left(56^{\circ} 47^{\prime} \mathrm{N}, 157^{\circ} 56^{\prime} \mathrm{E}\right)$ with extrusive dome of $2500 \mathrm{~m}$ above the sea level (Fig. 1b). Within the latest decade, its eruptions, determined by slow magma squeezing out and extrusive dome formation, are periodically accompanied by strong ash explosions. At that, in the cases of wind southern and south-western directions, eruptive cloud trajectories pass the sites KZY and KZV.

\section{References}

1. E.A. Mareev, Uspekhi Fizicheskikh Nauk, 180(5), 527- 533 (2010)

2. O.P. Rulenko, A.V. Ivanov, A.V. Shumeyko, Doklady Akademii Nauk, 326(6), 980982 (1992)

3. A.V. Buzevich, S.E. Smirnov, V.I. Filimonov, P.P. Firstov, Proc. of the International Conference «Solar-terrestrial bonds and electromagnetic precursors of earthquakes» (Petropavlovsk-Kamchatskiy: IKIR DVO RAN), 36-38 (1998)

4. S.E. Smirnov, Proc. of the school-seminar «Meteorological basis of magnetic observations of Siberia and Far East» (Petropavlovsk-Kamchatskiy, IKIR FEB RAS), 7-10 (2003)

5. G.I. Druzhin, D.V. Tarasenko, V.M. Pukhov, A.V. Zlygostev, Proc. of the II International Conference «Solar-terrestrial bonds and electromagnetic precursors of earthquakes» (Petropavlovsk-Kamchatskiy: IKIR DVO RAN), 32-33 (2001)

6. P.P. Firstov, R.R. Akbashev, R.R Holzworth, N.V. Cherneva, B.M. Shevtsov, Izvestiya Rossiyskoy Akademii Nauk. Fizika Atmosfery i Okeana - Izvestiya. Atmospheric and Oceanic Optics, 53(1) 29-37 (2017)

7. V.A. Efimov, D.M. Oreshkin, P.P. Firstov, R.R. Akbashev, Seysmicheskie pribory Seismic instruments, 49(4) 35-46 (2013)

8. E.A. Ponomarev, N.V. Cherneva, P.P. Firstov, Proc. of the 7th Intern. Conf. "Problems of Geocosmos" (St. Petersburg, Russia, 26-30 May 2008), 211-217 (2008)

9. E.A. Ponomarev, N.V. Cherneva, P.P. Firstov, Geomagnetizm i Aeronomiya Geomagnetism and Aeronomy, 3(51) 405-411 (2011)

10. P.P. Firstov, N.V. Cherneva, E.A. Ponomarev, A.V. Buzevich, Bulletin of KRAESC (Earth sciences, KGU), 1(7) 102-109 (2006)

11. M. R. James, S.J. Lane, J.S. Gilbert, J. Geol. Soc. London, 155, 587-590 (1998)

12. T.A. Mather, R.G. Harrison, Serv Geophys, 37, 387-432, (2006)

13. T. Miura, T. Koyaguchi, Y. Tanaka, Bull Volcanol, 64, 75-93 (2002)

14. N.V. Cherneva, E.A. Ponomarev, P.P. Firstov, A.V. Buzevich, Bulletin of KRAESC (Earth sciences, KGU), 2(10), 60-64 (2007) 